\title{
Nitrous Oxide
}

National Cancer Institute

\section{Source}

National Cancer Institute. Nitrous Oxide. NCI Thesaurus. Code C73617.

A naturally occurring gas that is colorless and non flammable. It can be manufactured and used for a variety of things such as a pharmacologic agent to produce anesthesia, a food additive as a propellant, and an additive to fuels to increase available oxygen in combustion. 